Pacific Journal of Mathematic 


\title{
ON ENTIRE FUNCTIONS OF INFINITE ORDER WITH RADIALLY DISTRIBUTED ZEROS
}

\author{
JOSEPH MiLeS
}

\begin{abstract}
Suppose $f$ is an entire function of infinite order with zeros restricted to a finite number of rays through the origin. It is shown for $p>1$ that $N(r, 0)=o\left(m_{p}^{+}(r, f)\right)$ where $m_{p}^{+}(r, f)$ is the $L^{p}$ norm of $\log ^{+}\left|f\left(r e^{i \theta}\right)\right|$ and in addition that $N(r, 0)=o(T(r, f))$ as $r$ tends to infinity omitting values in an exceptional set $E$ of zero logarithmic density. The set $E$ is shown by example in general to be nonempty, even for functions with zeros on a single ray and arbitrarily slow infinite rate of growth. These results settle certain questions arising from previous work of Edrei, Fuchs, and Hellerstein and of Hellerstein and Shea.
\end{abstract}

Introduction. In this paper we prove two theorems involving the rate of growth of an entire function $f$, the angular distribution of its zeros, and the Nevanlinna deficiency $d(0, f)$ of zero, defined to be

$$
d(0, f) \equiv 1-\limsup _{r \rightarrow \infty} N(r, 0) / T(r, f),
$$

where $N(r, 0)$ is the usual integrated counting function of the zeros of $f$ and $T(r, f)$ is the Nevanlinna characteristic. Conditions on the rate of growth of $f$ and on the arguments of its zeros sufficient to imply $d(0, f)>0$ have been known for some time [1, Theorem 2]. Of particular interest here is the following result of Edrei, Fuchs, and Hellerstein [3, Theorem 2].

THEOREM A. Suppose $f$ is an entire function with zeros restricted to the $K$ distinct rays arg $z=\alpha_{j}, 1 \leqq j \leqq K$. There exists $K^{\prime}=K^{\prime}\left(\alpha_{1}, \cdots, \alpha_{K}\right)$ and an absolute constant $A \in(0,1)$ such that if $f$ has finite order $\lambda>K^{\prime}$ then $d(0, f)>B_{\lambda}$ for some $B_{\lambda}>A$.

Later Hellerstein and Shea [7] showed that in Theorem A the quantity $B_{\lambda}$ can be chosen so that $B_{\lambda} \rightarrow 1$ as $\lambda \rightarrow \infty$, and in addition obtained a sharp asymptotic bound for $B_{\lambda}$ in the case that the zeros of $f$ are real. (For other related results, see [4], [5, Chapter 6], [8], and [11].)

In view of Theorem $A$ and the above result of Hellerstein and Shea, it is natural to ask [6, Problem 1.12] if $d(0, f)>0$ or even $d(0, f)=1$ for entire $f$ of infinite order with zeros on only a finite number of rays through the origin. We answer this question in the 
negative and explore certain related questions by proving the following two theorems. (We recall that a nondecreasing function $\varphi:(-\infty, \infty) \rightarrow[0, \infty)$ is strongly convex if it is convex and $\varphi(x) / x \rightarrow \infty$ as $x \rightarrow \infty$.)

THEOREM 1. Suppose $f$ is entire of infinite order with zeros restricted to a finite number of rays through the origin. Then

$$
\lim _{r \rightarrow \infty} \int_{0}^{2 \pi} \varphi\left(\frac{\log ^{+}\left|f\left(r e^{i \theta}\right)\right|}{N(r, 0)}\right) d \theta=\infty
$$

for every strongly convex function $\varphi$ and in particular for $p>1$

$$
\lim _{r \rightarrow \infty} \frac{N(r, 0)}{m_{p}^{+}(r, f)}=0
$$

where

$$
m_{p}^{+}(r, f)=\left(\frac{1}{2 \pi} \int_{0}^{2 \pi}\left(\log ^{+}\left|f\left(r e^{i \theta}\right)\right|\right)^{p} d \theta\right)^{1 / p} .
$$

Furthermore there exists a set $E \subset[1, \infty)$ having logarithmic density zero such that

$$
\lim _{\substack{r \rightarrow \infty \\ r \notin E}} \frac{N(r, 0)}{T(r, f)}=0
$$

In general under the above hypotheses $N(r, 0) / T(r, f)$ does not tend to zero as $r$ tends to infinity without restriction, even for functions with zeros on a single ray and arbitrarily slow infinite rate of growth, as is shown by

THEOREM 2. Suppose $\kappa:(0, \infty) \rightarrow(0, \infty)$ is such that $\kappa(r) \rightarrow \infty$ as $r \rightarrow \infty$. Associated with $\kappa$ there exists an entire $f$ having infinite lower order and positive zeros which satisfies $d(0, f)=0$ and

$$
\frac{\log T(r, f)}{\log r}<\kappa(r)
$$

for sufficiently large $r$.

Our approach to both Theorem 1 and Theorem 2 is to study $f$ via the Fourier series of $\log \left|f\left(r e^{i \theta}\right)\right|$. We prove (3) by in fact showing that as $r$ tends to infinity through values not in $E$, the ratio of $N(r, 0)$ to the maximum term of the Fourier series of $\log \left|f\left(r e^{i \theta}\right)\right|$ tends to zero. In our proof of Theorem 2 we achieve $d(0, f)=0$ by constructing $f$ so that, for an appropriate sequence 
$r_{n}$ tending to $\infty$, the Fourier series of $\log \left|f\left(r_{n} e^{i \theta}\right)\right|$ is approximated, in a suitable sense, by the Fourier series of the product of $N\left(r_{n}, 0\right)$ and a certain Poisson kernel. Because of the intricate nature of this construction, we provide an overview of the proof of Theorem 2 at the beginning of $\S 3$.

We assume familiarity with the notation of Nevanlinna theory. Throughout the remainder of the paper we abbreviate $n(r, 0)$ by $n(r)$ and $N(r, 0)$ by $N(r)$. It is not intended that the constant $m_{0}$ have the same value with each occurrence.

1. Preliminaries. We recall for entire $f$ the formulas, apparently first noticed by F. Nevanlinna [10], for the Fourier coefficients $c_{m}(r, f)$ of $\log \left|f\left(r e^{i \theta}\right)\right|$. If $f(0)=1$ and $\log f(z)=\sum a_{m} z^{m}$ near 0 , then for $m=1,2,3, \cdots$

$$
\begin{aligned}
c_{m}(r, f) & =\frac{1}{2 \pi} \int_{0}^{2 \pi} \log \left|f\left(r e^{i \theta}\right)\right| e^{-i m \theta} d \theta \\
& =\frac{a_{m}}{2} r^{m}+\frac{1}{2 m} \sum_{\left|z_{\nu}\right| \leqq r}\left(\left(\frac{r}{z_{\nu}}\right)^{m}-\left(\frac{\bar{z}_{\nu}}{r}\right)^{m}\right),
\end{aligned}
$$

where $\left\{z_{\nu}\right\}$ denotes the sequence of zeros of $f$ repeated according to multiplicity. Clearly

$$
c_{m}(r, f)=\overline{c_{-m}(r, f)}, \quad m=-1,-2,-3, \cdots,
$$

and $c_{0}(r, f)=N(r)$. A proof of these identities can be found in many places, including [9].

The following lemma is used in the proof of Theorem 1 . Its essential idea is due to Weyl [13] and it appears in a form similar to that given below in [3, pp. 149-151]. We include its proof for completeness.

Lemma 1.1. Suppose $\alpha_{1}, \alpha_{2}, \cdots, \alpha_{K}$ are distinct elements of $[0,2 \pi)$. For real $x$, let $x^{*}$ denote the unique number in $[-\pi, \pi)$ congruent to $x$ modulo $2 \pi$. There exists an increasing sequence $I=\left\{n_{q}\right\}$ of positive integers such that $I$ has positive density and

$$
\left(n_{q} \alpha_{j}\right)^{*} \in\left(-\frac{\pi}{6}, \frac{\pi}{6}\right)
$$

for $1 \leqq j \leqq K$ and $q=1,2,3, \cdots$.

Proof. Without loss of generality we assume no $\alpha_{j}$ is zero. Let $\omega_{j}=\alpha_{j} / 2 \pi$ for $1 \leqq j \leqq K$. Let $M(\leqq K)$ be the maximum number of the $\omega_{j}$ which are linearly independent over the integers. Re- 
numbering if necessary, we assume $\omega_{1}, \omega_{2}, \cdots, \omega_{M}$ are linearly independent over the integers.

If $M=K$, we let $B=1$. If $M<K$, we define $B$ as follows. For $M<p \leqq K$, there exists an integer $\sigma>0$ and integers $m_{p j}$ such that

$$
\sigma \omega_{p}=\sum_{j=1}^{M} m_{p j} \omega_{j}
$$

Set

$$
B_{p}=\sum_{j=1}^{M}\left|m_{p j}\right|, \quad M<p \leqq K,
$$

and

$$
B=\sup \left(\sigma, B_{M+1}, B_{M+2}, \cdots, B_{K}\right) .
$$

By a theorem of Weyl [13, Satz 16], since $\omega_{1}, \omega_{2}, \cdots, \omega_{M}$ are linearly independent over the integers, there exists a sequence $I^{\prime}$ of positive integers $u_{q}$ having positive density such that for $q=1,2,3, \cdots$

$$
\left|u_{q} \omega_{j}-L_{q j}\right|<\frac{1}{12 B}, \quad 1 \leqq j \leqq M,
$$

for some integers $L_{q j}$. Thus in the case that $M=K$, the proof is finished by (1.4) upon setting $I=I^{\prime}$ and $n_{q}=u_{q}$.

Suppose $M<K$. We note for all $q=1,2,3, \cdots$

$$
\left|\sigma u_{q} \omega_{j}-\sigma L_{q j}\right|<\frac{\sigma}{12 B} \leqq \frac{1}{12}, \quad 1 \leqq j \leqq M
$$

If $p>M$, then for all $q$ by (1.3) and (1.4)

$$
\sigma u_{q} \omega_{p}=\sum_{j=1}^{M} m_{p j} u_{q} \omega_{j}=\sum_{j=1}^{M} m_{p j}\left(L_{q j}+\delta_{q j}\right)
$$

for some $\delta_{q j}$ with $\left|\delta_{q j}\right|<(12 B)^{-1}$ for $1 \leqq j \leqq M$ and $q=1,2,3, \cdots$. For $M<p \leqq K$ and all $q$, we set

$$
C_{p q}=\sum_{j=1}^{M} m_{p j} L_{q j}
$$

and notice that

$$
\begin{gathered}
\left|\sigma u_{q} \omega_{p}-C_{p q}\right| \leqq \sum_{j=1}^{M}\left|m_{p j}\right|\left|\delta_{q j}\right| \\
<\frac{B_{p}}{12 B} \leqq \frac{1}{12}
\end{gathered}
$$


From (1.5) and (1.6), we see that $I=\left\{n_{q}\right\}$ with $n_{q}=\sigma u_{q}$ satisfies all requirements of the lemma.

Our proof of Theorem 1 also requires

LEMMA 1.2. If $\left\{n_{q}\right\}$ is an increasing sequence of positive integers which has positive density, then there exists a subsequence $n_{q_{k}}=m_{k}$ such that

$$
\text { (i) } m_{k+1} / m_{k} \rightarrow 1
$$

and

$$
\text { (ii) } \sum_{k=1}^{\infty} \frac{1}{m_{k+1}-m_{k}}<\infty \text {. }
$$

Proof. The fact that $\left\{n_{q}\right\}$ has positive density implies $n_{q+1} / n_{q} \rightarrow 1$. We let

$$
\gamma_{q}=\max \left\{n_{p+1} / n_{p}: p \geqq q\right\}
$$

and note that $\gamma_{q} \rightarrow 1$. For each $q$ and each $a>1$ it follows that there exists an integer $p \geqq q$ such that

$$
a \leqq n_{p} / n_{q} \leqq a \gamma_{q} \text {. }
$$

We let $n_{q_{1}}=m_{1}$ be arbitrary and see from (1.8) that there exists a subsequence $n_{q_{k}}=m_{k}$ such that for $k=1,2,3, \cdots$

$$
\left(1+\frac{3}{k}\right) \leqq \frac{m_{k+1}}{m_{k}} \leqq\left(1+\frac{3}{k}\right) \gamma_{q_{k}},
$$

establishing (1.7i). Certainly (1.9) guarantees

$$
\log m_{k}>3 \log k-0(1),
$$

which in conjunction with (1.9) yields

$$
\frac{1}{m_{k+1}-m_{k}}<\frac{1}{m_{k+1}\left(1-\left(1+\frac{3}{k}\right)^{-1}\right)}=O\left(\frac{1}{k^{2}}\right),
$$

establishing (1.7ii).

2. Proof of Theorem 1. We begin with

LEMMA 2.1. Suppose $f$ is entire of infinite order with zeros on the distinct rays $\arg z=\alpha_{j} \in[0,2 \pi), 1 \leqq j \leqq K$. If $r_{n} \rightarrow \infty$ such that

$$
\liminf _{n \rightarrow \infty} \frac{N\left(r_{n}\right)}{T\left(r_{n}, f\right)}>0,
$$


then there exists $\eta_{1}, \eta_{2}, \cdots, \eta_{K}$ in $[0,1]$ with $\sum_{j=1}^{K} \eta_{j}=1$ and there exists a subsequence of $r_{n}$ (still denoted by $r_{n}$ ) such that

$$
\lim _{n \rightarrow \infty} \frac{c_{m}\left(r_{n}, f\right)}{N\left(r_{n}\right)}=\sum_{j=1}^{K} \eta_{j} e^{-i m \alpha_{j}}
$$

for all integers $m$.

Proof. Without loss of generality we suppose $f(0)=1$. Let $N_{j}(t)$ be the integrated counting function of the zeros of $f$ on the ray $\arg z=\alpha_{j}$. By passing to a subsequence if necessary, we may assume

$$
N_{j}\left(r_{n}\right) / N\left(r_{n}\right) \longrightarrow \eta_{j} \in[0,1]
$$

with $\sum_{j=1}^{K} \eta_{j}=1$.

We write

$$
f(z)=e^{h(z)} \prod_{j=1}^{K} f_{j}(z)
$$

with

$$
f_{j}(z)=\prod_{\nu} E\left(\frac{z}{z_{\nu j}}, \nu\right)
$$

where $z_{\nu j}$ is the sequence of zeros of $f$ on $\arg z=\alpha_{j}$ repeated according to multiplicity and arranged in order of increasing modulus. If $h(z)=\sum a_{m} z^{m}$, then for $m=1,2,3, \cdots$

$$
c_{m}(r, f)=\frac{a_{m}}{2} r^{m}+\sum_{j=1}^{K} c_{m}\left(r, f_{j}\right)
$$

where by (1.1)

$$
c_{m}\left(r, f_{j}\right)=\frac{1}{2 m} \sum_{\left|z_{\nu j}\right| \leqq r}\left(\left(\frac{r}{z_{\nu j}}\right)^{m}-\left(\frac{\bar{z}_{\nu j}}{r}\right)^{m}\right)-\frac{1}{2 m} \sum_{\nu<m}\left(\frac{r}{z_{\nu j}}\right)^{m} .
$$

Two integrations by parts yield

$$
c_{m}(r, f)=\frac{a_{m}}{2} r^{m}+\sum_{j=1}^{K} e^{-i m \alpha_{j}}\left(g_{j m}(r)+N_{j}(r)+d_{j m} r^{m}\right)
$$

where

$$
d_{j m}=-\frac{1}{2 m} \sum_{\nu<m} \frac{1}{\left|z_{\nu j}\right|^{m}}
$$

and

$$
g_{j m}(r)=\frac{m}{2} \int_{0}^{r}\left(\left(\frac{r}{t}\right)^{m}-\left(\frac{t}{r}\right)^{m}\right) \frac{N_{j}(t)}{t} d t .
$$


We set

$$
g_{m}(r)=\sum_{j=1}^{K} g_{j m}(r)
$$

Certainly the lower order of $f$ is infinite. This fact (first established in [2]) can be deduced as follows. If $N(r)$ has finite order, then $f$, an entire function of infinite order, can be represented as the product of an entire function of finite order and a zero-free entire function, trivially implying the lower order of $f$ is infinite. Suppose on the other hand that $N(r)$ has infinite order and let $I$ be the sequence of integers of Lemma 1.1. By (2.4) for each fixed $m \in I$ we have as $r \rightarrow \infty$

$$
\begin{aligned}
\operatorname{Re} \frac{c_{m}(r, f)}{r^{m}} & \geqq \frac{\sqrt{3}}{2}\left(r^{-m} g_{m}(r)+r^{-m} N(r)\right)+O(1) \\
& \geqq \frac{m \sqrt{3}}{8} \int_{0}^{r / 2} \frac{N(t)}{t^{m+1}} d t+O(1) .
\end{aligned}
$$

By Nevanlinna's First Fundamental Theorem,

$$
\left|c_{m}(r, f)\right| \leqq 2 T(r, f)
$$

for all $m$. Since $N(r)$ has infinite order, we conclude from (2.5) and (2.6) that $f$ has infinite lower order.

From (2.1) we thus conclude

$$
\lim _{n \rightarrow \infty} \frac{r_{n}^{m}}{N\left(r_{n}\right)}=0, \quad m=1,2,3, \cdots .
$$

We next establish

$$
g_{m}\left(r_{n}\right)=o\left(N\left(r_{n}\right)\right), \quad m=1,2,3, \cdots .
$$

If (2.8) were false, there would exist a positive integer $m_{0}, \varepsilon>0$, and a subsequence of $r_{n}$ (still denoted by $r_{n}$ ) such that

$$
g_{m_{0}}\left(r_{n}\right)>\varepsilon N\left(r_{n}\right)
$$

for all $n$. Since $g_{m}(r) / m$ is an increasing function of $m$ for each fixed $r>0$, for $m>m_{0}$ and $m \in I$ we have

$$
g_{m}\left(r_{n}\right)>\frac{m}{m_{0}} g_{m_{0}}\left(r_{n}\right)>\frac{m \varepsilon}{m_{0}} N\left(r_{n}\right), \quad n=1,2,3, \cdots
$$

and hence by (2.5) and (2.7) 


$$
\begin{aligned}
\operatorname{Re} c_{m}\left(r_{n}, f\right) & \geqq \frac{\sqrt{3}}{2}\left(g_{m}\left(r_{n}\right)+N\left(r_{n}\right)\right)+O\left(r_{n}^{m}\right) \\
& \geqq \frac{\sqrt{3}}{2}\left(\frac{m \varepsilon}{m_{0}}+1\right) N\left(r_{n}\right)+O\left(r_{n}^{m}\right) \\
& \geqq \frac{\sqrt{3}}{2}\left(\frac{m \varepsilon}{m_{0}}+1+o(1)\right) N\left(r_{n}\right) .
\end{aligned}
$$

Since $m \in I$ may be chosen arbitrarily large, (2.6) and (2.9) contradict (2.1), establishing (2.8).

For an arbitrary positive integer $m$, we now set $r=r_{n}$ in (2.4), divide by $N\left(r_{n}\right)$, and appeal to (2.3), (2.7), and (2.8) to deduce (2.2). For negative indices, (2.2) is established by conjugation. Its truth for $m=0$ is obvious. This proves Lemma 2.1.

We now prove (1). If (1) were false, there would exist a strongly convex $\varphi$ and a sequence $r_{n} \rightarrow \infty$ such that

$$
\sup _{n} \int_{0}^{2-\pi} \varphi\left(\frac{\log ^{+}\left|f\left(r_{n} e^{i \theta}\right)\right|}{N\left(r_{n}\right)}\right) d \theta<\infty \text {. }
$$

Thus (2.1) would hold for $r_{n}$, and by Lemma 2.1 we may consider a subsequence (still denoted by $r_{n}$ ) for which (2.2) holds. We seek a contradiction.

Nevanlinna's First Fundamental Theorem and (2.1) imply that the sequence of measures on the unit circle $T$ defined by

$$
d \mu_{n}=\frac{\log \left|f\left(r_{n} e^{i \theta}\right)\right|}{2 \pi N\left(r_{n}\right)} d \theta
$$

is bounded in total variation norm, say by $L$. We show that the measures (2.11) converge weakly to the measere on $T$ with point mass at $e^{i \alpha_{j}}$ having weight $\eta_{j}$. Suppose $g$ is a continuous function on $T$ and let $P$ be a trigonometric polynomial. We have

$$
\begin{aligned}
w_{n} \equiv & \frac{1}{2 \pi} \int_{-\pi}^{\pi} \frac{\log \left|f\left(r_{n} e^{i \theta}\right)\right|}{N\left(r_{n}\right)} g\left(e^{i \theta}\right) d \theta-\sum_{j=1}^{K} \eta_{j} g\left({ }^{i \alpha_{j}}\right) \\
= & \frac{1}{2 \pi} \int_{-\pi}^{\pi} \frac{\log \left|f\left(r_{n} e^{i \theta}\right)\right|}{N\left(r_{n}\right)}\left(g\left(e^{i \theta}\right)-P\left(e^{i \theta}\right)\right) d \theta \\
& +\frac{1}{2 \pi} \int_{-\pi}^{\pi} \frac{\log \left|f\left(r_{n} e^{i \theta}\right)\right|}{N\left(r_{n}\right)} P\left(e^{i \theta}\right) d \theta-\sum_{j=1}^{K} \eta_{j} g\left(e^{i \alpha_{j}}\right) \\
\equiv & x_{n}+y_{n}-\sum_{j=1}^{K} \eta_{j} g\left(e^{i \alpha_{j}}\right),
\end{aligned}
$$

where

$$
\left|x_{n}\right| \leqq L\|g-P\|_{\infty}
$$

and, by (2.2), 


$$
\lim _{n \rightarrow \infty} y_{n}=\sum_{j=1}^{K} \eta_{j} P\left(e^{i \alpha_{j}}\right) .
$$

Since $\sum_{j=1}^{K} \eta_{j}=1$, these last two observations imply

$$
\left|w_{n}\right| \leqq(L+1)\|g-P\|_{\infty}+o(1), \quad(n \longrightarrow \infty) .
$$

Since the trigonometric polynomials are dense in the continuous functions on $T$, the asserted weak convergence is established.

Without loss of generality we suppose $\eta_{1}>0$. Let $\delta>0$ be such that the arc $J=\left\{e^{i \theta}:\left|\theta-\alpha_{1}\right|<\delta\right\}$ contains no point $e^{i \alpha_{j}}$ for $2 \leqq j \leqq K$. Let $g: T \rightarrow[0,1]$ be a continuous function vanishing on $T-J$ with $g\left(e^{i \alpha_{1}}\right)=1$. In view of the weak convergence of the measures $d \mu_{n}$, for $n>n_{0}(g)$

$$
\begin{aligned}
\frac{\eta_{1}}{2} & <\frac{1}{2 \pi} \int_{-\pi}^{\pi} \frac{\log \left|f\left(r_{n} e^{i \theta}\right)\right|}{N\left(r_{n}\right)} g\left(e^{i \theta}\right) d \theta \\
& \leqq \frac{1}{2 \pi} \int_{\alpha_{1}-\delta}^{\alpha_{1}+\delta} \frac{\log ^{+}\left|f\left(r_{n} e^{i \theta}\right)\right|}{N\left(r_{n}\right)} d \theta .
\end{aligned}
$$

Thus $\left\{\log ^{+}\left|f\left(r_{n} e^{i \theta}\right)\right| / N\left(r_{n}\right)\right\}$ is not a uniformly integrable family and it follows by standard arguments [12, pp. 37-38] that (2.10) cannot hold, giving the desired contradiction.

For $p>1$ the choice in (1) of $\varphi(t)=t^{p}$ if $t \geqq 0$ and $\varphi(t)=0$ if $t<0$ establishes (2).

We now turn to the proof of (3) and again assume with no loss in generality that $f(0)=1$. In view of Lemmas 1.1 and 1.2 , we may now let $I=\left\{m_{l k}\right\}$ be an increasing sequence of positive integers satisfying (1.7i and ii) and, in addition,

$$
\left(m_{k} \alpha_{j}\right)^{*} \in\left(-\frac{\pi}{6}, \frac{\pi}{6}\right)
$$

for $1 \leqq j \leqq K$ and $k=1,2,3, \cdots$.

Since $f$ has infinite lower order (note the discussion leading to (2.5) does not use hypothesis (2.1)), we may assume $N(r)$ has infinite order. For $m=1,2,3, \cdots$ we define a nondecreasing unbounded sequence $s_{m}$ by

$$
s_{m}=\inf \{t \geqq e: \log n(t) / \log t \geqq m / 2\} .
$$

Thus

$$
n(t)<t^{m / 2}, \quad e \leqq t<s_{m} .
$$

Again letting $z_{\nu j}$ be the zeros of $f$ on $\arg z=\alpha_{j}$ repeated according to multiplicity, we represent $f$ as 


$$
f(z)=e^{I(z)} \prod_{j=1}^{K} G_{j}(z)
$$

where $H(z)=\sum B_{m} z^{m}$ is entire and

$$
G_{j}(z)=\prod_{\nu} E\left(\frac{z}{z_{\nu j}}, q_{\nu}\right)
$$

where $q_{\nu}=m$ if $s_{m} \leqq\left|z_{\nu j}\right|<s_{m+1}$ and $q_{\nu}=0$ if $\left|z_{\nu j}\right|<s_{1}$. We show the product (2.14) converges to an entire function by establishing

$$
\sum_{\nu}\left(\frac{r}{\left|z_{\nu j}\right|}\right)^{q_{\nu}+1}<\infty
$$

for every $r>0$. Letting $\widetilde{n}_{j}(t)$ be the number of zeros of $G_{j}$ in $|z|<t$, we have from (2.13) for $m=1,2,3, \cdots$

$$
\begin{aligned}
& \sum_{s_{m} \leqq\left|z_{\nu j}\right|<s_{m+1}}\left(\frac{r}{\left|z_{\nu j}\right|}\right)^{q_{\nu}+1}=\int_{s_{m}}^{s_{m+1}}\left(\frac{r}{t}\right)^{m+1} d \widetilde{n}_{j}(t) \\
& \leqq \frac{r^{m+1} \widetilde{n}_{j}\left(s_{m+1}\right)}{s_{m+1}^{m+1}}+(m+1) \int_{s_{m}}^{s_{m+1}}\left(\frac{r}{t}\right)^{m+1} \frac{\widetilde{n}_{j}(t)}{t} d t \\
& \leqq\left(\frac{r}{\boldsymbol{s}_{m+1}^{1 / 2}}\right)^{m+1}+2\left(\frac{r}{\boldsymbol{s}_{m}^{1 / 2}}\right)^{m+1} \leqq 3\left(\frac{r}{\boldsymbol{s}_{m}^{1 / 2}}\right)^{m+1} .
\end{aligned}
$$

Thus if $s_{m_{0}}>4 r^{2}$, then

$$
\sum_{\mid z_{\nu j} \backslash s_{m_{0}}}\left(\frac{r}{\left|z_{\nu j}\right|}\right)^{q_{\nu}+1} \leqq \frac{3}{2^{m_{0}}}
$$

establishing (2.15).

Certainly for positive $m$

$$
c_{m}(r, f)=\frac{B_{m}}{2} r^{m}+\sum_{j=1}^{K} c_{m}\left(r, G_{j}\right),
$$

where by (1.1)

$$
\begin{aligned}
\boldsymbol{c}_{m}\left(r, G_{j}\right)= & e^{-i m \alpha_{j}}\left\{\frac{1}{2 m} \sum_{\mid z_{\nu j} ! \leqq r}\left(\left(\frac{r}{\left|z_{\nu j}\right|}\right)^{m}-\left(\frac{\left|\boldsymbol{z}_{\nu j}\right|}{\boldsymbol{r}}\right)^{m}\right)\right. \\
& \left.-\frac{1}{2 m} \sum_{q_{\nu}<m}\left(\frac{\boldsymbol{r}}{\left|\boldsymbol{z}_{\nu j}\right|}\right)^{m}\right\} .
\end{aligned}
$$

Since $q_{\nu}<m$ is equivalent to $\left|z_{\nu j}\right|<s_{m}$, integration by parts yields

$$
\begin{aligned}
& c_{m}\left(r, G_{j}\right)=e^{-i m \alpha_{j}}\left\{r^{m}\left(\frac{-\widetilde{n}_{j}\left(s_{m}\right)}{2 m s_{m}^{m}}-\frac{N_{j}\left(s_{m}\right)}{2 s_{m}^{m}}\right)\right. \\
& \left.\quad+N_{j}(r)-\frac{m}{2} \int_{0}^{r}\left(\frac{t}{r}\right)^{m} \frac{N_{j}(t)}{t} d t+\frac{m}{2} \int_{s_{m}}^{r}\left(\frac{r}{t}\right)^{m} \frac{N_{j}(t)}{t} d t\right\} .
\end{aligned}
$$

Since $N(r) \leqq n(r) \log r+0(1)$, for large $m$ we have $N\left(s_{m}\right)<s_{m}^{3 m / 4}$ by (2.13). Combining (2.13), (2.17), and (2.19) we obtain 


$$
c_{m}(r, f)=\gamma_{m} r^{m}+\beta_{m}(r) N(r)+\frac{m}{2} \sum_{j=1}^{K} e^{-i m \alpha_{j}} \int_{s_{m}}^{r}\left(\frac{r}{t}\right)^{m} \frac{N_{j}(t)}{t} d t
$$

for a sequence of constants $\gamma_{m}$ with $\left|\gamma_{m}\right|^{1 / m} \rightarrow 0$ and a function $\beta_{m}(r)$ with $\left|\beta_{m}(r)\right|<1$ for all $r>0$ and all $m=1,2,3, \cdots$.

For $\gamma_{m} \neq 0$ we set $\gamma_{m}=\left|\gamma_{m}\right| e^{i \rho_{m}}, 0 \leqq \rho_{m}<2 \pi$, and let $V$ be the set of $m \in I$ with $\gamma_{m}=0$ or

$$
\left|\rho_{m}-\frac{q \pi}{2}\right|<\frac{\pi}{4} \text { for } q=1 \text { or } q=3 .
$$

For $m \in V$ it follows from (2.12), (2.20), (2.21), and elementary trigonometry that for $r>0$

$$
\begin{aligned}
& \left|c_{m}(r, f)-\beta_{m}(r) N(r)\right| \\
& \quad=\left|\gamma_{m} r^{m}+\frac{m}{2} \sum_{j=1}^{K} e^{-i m \alpha_{j}} \int_{s_{m}}^{r}\left(\frac{r}{t}\right)^{m} \frac{N_{j}(t)}{t} d t\right| \\
& \quad \geqq\left(\sin \frac{\pi}{12}\right) \frac{m}{2}\left|\sum_{j=1}^{K} e^{-i m \alpha_{j}} \int_{s_{m}}^{r}\left(\frac{r}{t}\right)^{m} \frac{N_{j}(t)}{t} d t\right| \\
& \quad \geqq \frac{\sqrt{3} m\left(\sin \frac{\pi}{12}\right)}{4}\left|\int_{s_{m}}^{r}\left(\frac{r}{t}\right)^{m} \frac{N(t)}{t} d t\right| .
\end{aligned}
$$

For $m \in V$, we set $b_{m}=s_{m}$.

For $m \in I-V$ we set

$$
\varphi_{m}(t)= \begin{cases}0 & N(t)=0 \\ \frac{1}{N(t)} \sum_{j=1}^{K} e^{-i\left(m \alpha_{j}+\rho_{m}\right)} N_{j}(t) & N(t)>0\end{cases}
$$

and note that for $N(t)>0$ the continuous function $\varphi_{m}$ satisfies

$$
\sin \frac{\pi}{12} \leqq\left|\operatorname{Re} \varphi_{m}(t)\right| \leqq 1
$$

Thus from (2.20) for $r>0$

$$
\begin{aligned}
& \operatorname{Re}\left(e^{-i \rho_{m}}\left(c_{m}(r, f)-\beta_{m}(r) N(r)\right)\right) \\
& \quad=\left|\gamma_{m}\right| r^{m}+\frac{m}{2} \int_{s_{m}}^{r}\left(\frac{r}{t}\right)^{m}\left(\operatorname{Re} \varphi_{m}(t)\right) \frac{N(t)}{t} d t .
\end{aligned}
$$

Since $N(t)$ has infinite order and $\left|\gamma_{m}\right|^{1 / m} \rightarrow 0$, it follows from (2.23) that for $m \in I-V$ there exists a sequence $b_{m} \rightarrow \infty$ such that $N\left(b_{m}\right)>0$ and

$$
\left|\gamma_{m}\right|=\frac{m}{2} \int_{b_{m}}^{s_{m}}\left(\operatorname{Re} \varphi_{m}(t)\right) \frac{N(t)}{t^{m+1}} d t
$$


for $m>m_{0}$. Thus by (2.23), (2.24), and (2.25) for $m>m_{0}$ and $r>0$

$$
\begin{aligned}
& \frac{\left|c_{m}(r, f)-\beta_{m}(r) N(r)\right|}{\sin \frac{\pi}{12}} \\
& \geqq \frac{m}{2 \sin \frac{\pi}{12}}\left|\int_{b_{m}}^{r}\left(\frac{r}{t}\right)^{m}\left(\operatorname{Re} \varphi_{m}(t)\right) \frac{N(t)}{t} d t\right| \\
& \geqq \frac{m}{2}\left|\int_{b_{m}}^{r}\left(\frac{r}{t}\right)^{m} \frac{N(t)}{t} d t\right| .
\end{aligned}
$$

Without loss of generality we may suppose $m_{0}$ is so large that $m_{0}<$ $m_{k} \in I$ implies $m_{k+1} / m_{k}<2$.

Let $I_{0}=I \cap\left(m_{0}, \infty\right)$. From (2.6), (2.22), and (2.26) we see that to prove (3), it is sufficient to demonstrate the existence of a set $E \subset[1, \infty)$ with logarithmic density zero such that

$$
\lim \frac{N(r)}{\sup _{m \in I_{0}}\left|m \int_{b_{m}}^{r}\left(\frac{r}{t}\right)^{m} \frac{N(t)}{t} d t\right|}=0
$$

as $r$ tends to infinity through values not in $E$.

For

$$
r \geqq x_{0} \equiv \min \left\{b_{m}: m \in I_{0}\right\},
$$

let

$$
\nu(r)=\max \left\{m: m \in I_{0} \text { and } b_{m} \leqq r\right\} .
$$

We denote by $S$ the range of the nondecreasing integer-valued function $\nu$. For $m=m_{k} \in S$, we let $m^{\prime}=m_{k+1}$. From the definition of $\nu$ we have

$$
J_{m} \equiv \nu^{-1}\{m\} \subset\left[b_{m}, b_{m^{\prime}}\right) .
$$

Furthermore

$$
\left[x_{0}, \infty\right)=\bigcup_{m \in S} J_{m},
$$

where the right side is a union of disjoint intervals. For $m \in S$ we define $0<\varepsilon_{m}<1$ by

$$
1+\varepsilon_{m}=m^{\prime} / m
$$

and note by (1.7i) that $\varepsilon_{m} \rightarrow 0$ as $m$ tends to infinity through values in $S$.

Letting $m_{l}$ denote logarithmic measure and letting $S_{1}$ be the set of $m \in S$ such that 


$$
m_{l}\left(J_{m}\right)<\frac{1}{m \varepsilon_{m}}
$$

we see from (1.7ii) and (2.30) that if

$$
E_{1}=\bigcup_{m \in S_{1}} J_{m}
$$

then

$$
m_{l}\left(E_{1}\right) \leqq \sum_{m \in S_{1}} \frac{1}{m^{\prime}-m}<\infty
$$

For $m \in S-S_{1}$ we consider an arbitrary interval $\widetilde{J}_{m} \subset J_{m}$ with

$$
m_{l}\left(\widetilde{J}_{m}\right)=\frac{1}{m \varepsilon_{m}}
$$

Since $d(\log N(t)) / d(\log t)=n(t) / N(t)$ assumes a given value $(m)$ at only a finite number of points in any bounded interval on which $n(t)>0$, we see that there exists a real $y_{m}=y_{m}\left(\widetilde{J}_{m}\right)$ such that

$$
A_{m} \equiv\left\{t \in \widetilde{J}_{m}: \log N(t)>m \log t+y_{m}\right\}
$$

satisfies

$$
m_{l}\left(A_{m}\right)=\frac{1}{m \varepsilon_{m}^{1 / 2}}
$$

We note that $r \in \widetilde{J}_{m}-A_{m}$ and $t \in A_{m}$ imply

$$
N(t)>N(r)(t / r)^{m}
$$

Given $r \in \widetilde{J}_{m}-A_{m}$, let

$$
A_{m}^{*}(r)=A_{m}^{*}=A_{m} \cap(0, r)
$$

and

$$
A_{m}^{* *}(r)=A_{m}^{* *}=A_{m} \cap(r, \infty)
$$

Thus either

$$
m_{l}\left(A_{m}^{*}\right) \geqq \frac{1}{2 m \varepsilon_{m}^{1 / 2}}
$$

or

$$
m_{l}\left(A_{m}^{* *}\right) \geqq \frac{1}{2 m \varepsilon_{m}^{1 / 2}}
$$

In the former case by (2.28) and (2.34) 


$$
\begin{gathered}
m \int_{b_{m}}^{r}\left(\frac{r}{t}\right)^{m} \frac{N(t)}{t} d t \geqq m \int_{A_{m}^{*}}\left(\frac{r}{t}\right)^{m} \frac{N(t)}{t} d t \\
\geqq m N(r) m_{l}\left(A_{m}^{*}\right) \geqq \frac{N(\boldsymbol{r})}{2 \varepsilon_{m}^{1 / 2}} .
\end{gathered}
$$

In the latter case by (2.28), (2.30), and (2.34)

$$
\begin{gathered}
m^{\prime} \int_{r}^{b_{m^{\prime}}}\left(\frac{r}{t}\right)^{m^{\prime}} \frac{N(t)}{t} d t \geqq m^{\prime} N(r) \int_{A_{m}^{* *}}\left(\frac{t}{r}\right)^{m-m^{\prime}} \frac{d t}{t} \\
\geqq m^{\prime} N(r) m_{l}\left(A_{m}^{* *}\right) \min _{t \in A_{m}^{* *}}\left(\frac{t}{r}\right)^{-m \varepsilon_{m}} \\
\geqq \frac{m^{\prime} N(r)}{2 e m \varepsilon_{m}^{1 / 2}}=\frac{\left(1+\varepsilon_{m}\right) N(r)}{2 e \varepsilon_{m}^{1 / 2}},
\end{gathered}
$$

since for $t \in A_{m}^{* *}$

$$
\begin{gathered}
\log \left(\frac{t}{r}\right)^{-m \varepsilon_{m}}=-m \varepsilon_{m}(\log t-\log r) \\
\geqq-m \varepsilon_{m} m_{l}\left(\widetilde{J}_{m}\right)=-1 .
\end{gathered}
$$

From (2.32), (2.33), (2.35), and (2.36) we see there exists a set

$$
E_{2} \subset E_{3} \equiv \bigcup_{m \in S-S_{1}} J_{m}
$$

for which

$$
m_{l}\left(E_{2} \cap\left[x_{0}, r\right)\right)=o\left(m_{l}\left(E_{3} \cap\left[x_{0}, r\right)\right)\right)=o(\log r)
$$

and such that (2.27) holds as $r$ tends to infinity through values in $E_{3}-E_{2}$. Combined with (2.29) and (2.31), this establishes (2.27) with $E=E_{1} \cup E_{2}$ and thus proves (3).

3. Proof of Theorem 2. Due to the complicated nature of our construction, we begin with a brief outline of the proof of Theorem 2. We first construct an entire $g$ with zero counting function $N(r)$ having the property that $\log N(r)$ is approximately a piecewise-linear convex function of $\log r$ (see (3.10)) such that, for a sequence $r_{n}$ tending to infinity, $d(\log N(t)) / d(\log t)$ evaluated at $t=r_{n}$ is much larger (approximately $M_{n}^{2}$ ) than is $\log N\left(r_{n}\right) / \log r_{n}$ (approximately $M_{n}$ ). (See (3.18) and the remarks immediately preceding it.) This key property enables us to construct polynomials $h_{n}$ so that an initial segment of the Fourier series of $e^{h} n g$ differs in $L^{2}$ norm from the corresponding portion of the Fourier series of

$$
\left(\operatorname{Re} \frac{1+\beta_{n} e^{i \theta}}{1-\beta_{n} e^{i \theta}}\right) N\left(r_{n}\right)>0
$$


by $o\left(N\left(r_{n}\right)\right)$. (See (3.26) and (3.28).) Because the sequence $r_{n}$ is sufficiently well spaced, from the polynomials $h_{n}$ we are able to construct an entire $h$ (see (3.38)) so that the Fourier series of $\log |f|=\log \left|e^{h} g\right|$ behaves on $|z|=r_{n}$ much like that of $\log \left|e^{h_{n}} g\right|$, leading to (3.53) and implying $d(0, f)=0$.

It would seem a fair observation that the essential difference between the infinite order and finite order situations is that in the former case infinitely many coefficients of $h(z)=\sum a_{m} z^{m}$ are at our disposal, subject only to the condition $\left|a_{m}\right|^{1 / m} \rightarrow 0$, and that they may in fact be so chosen as to achieve $N\left(r_{n}\right) / T\left(r_{n}, f\right) \rightarrow 1$ on a widely spaced sequence; on the other hand, for $f$ of finite order, only finitely many nonzero $a_{m}$ are at our disposal and the approach employed below is clearly unavailable. Finally, we remark that much of the intricacy of the construction is a result of the requirement that $f$ grow slowly in the sense of (4).

We now turn to the details of the proof and begin with

Lemma 3.1. Suppose $\gamma:(0, \infty) \rightarrow(0, \infty)$ is a nondecreasing function with $\gamma(x) / x \rightarrow \infty$ as $x \rightarrow \infty$. For $x>4$, let $\gamma_{1}(x)=\gamma((x-4) / 4)$. There exist sequences of positive integers $M_{n}$ and $x_{n}$ tending to infinity, a positive sequence $\beta_{n}$ tending upward to 1 , and $a$ piecewise-linear convex function $\varphi:\left[x_{1}, \infty\right) \rightarrow[1, \infty)$ such that

(i) $\quad M_{n+1} \geqq n M_{n}^{4}, n=1,2,3, \cdots$;

(ii) $\frac{\beta_{n}^{2 M_{n+1}}}{1-\beta_{n}}<\frac{1}{n}, n=1,2,3, \cdots$;

(iii) $\frac{x_{n+1}}{x_{n}}=16 j_{n}, j_{n}=$ integer, $n=1,2,3, \cdots$;

(iv) $1-\beta_{n+1}^{m}<e^{-4 m x_{n}}, M_{n+1} \leqq m \leqq 2 M_{n+1}, n=1,2,3, \cdots$;

(v) $\varphi(x) \leqq \gamma_{1}(x), x \geqq x_{1}$;

(vi) $\varnothing$ is convex on $\left[x_{n}, x_{n+1}\right]$, linear on $\left[x_{n}, 8 x_{n}\right]$, and linear on each segment $\left[8 x_{n}+4 k, 8 x_{n}+4(k+1)\right]$ contained in $\left[x_{n}, x_{n+1}\right], k=$ integer, $n=1,2,3, \cdots$;

(vii) $\varphi^{\prime}(x) \leqq\left(\varphi^{\prime}(x-4)\right)^{4}, x \geqq x_{1}+4$, where $\varphi^{\prime}$ denotes the right derivative of $\varphi$;

(viii) $M_{n}^{2}=\varphi^{\prime}\left(x_{n}\right) \leqq \varphi^{\prime}(x) \leqq M_{n+1}^{1 / 2}, x_{n} \leqq x<x_{n+1}, n=1,2,3, \cdots$;

(ix) $\frac{\varphi\left(x_{n}\right)}{x_{n}} \leqq M_{n}^{1 / 2}, n=1,2,3, \cdots$;

(x) $\varphi\left(x_{n}\right)+M_{n+1}^{1 / 2}\left(x-x_{n}\right)+M_{n+2}^{1 / 2}\left(x-x_{n+1}\right)<\gamma_{1}(x)$ for $x \geqq x_{n+1}$, $n=1,2,3, \cdots$;

and

(xi) $4 M_{n+1} x<\gamma_{1}(x), x \geqq x_{n}, n=1,2,3, \cdots$.

Proof of Lemma 3.1. We let $M_{1}=2$ and let $M_{2}$ be an arbitrary 
integer greater than $M_{1}^{4}$. Let $0<\beta_{1}<1$ be such that (3.1 ii) holds with $n=1$. Let $x_{1}$ be an integer greater than 4 so large that $(3.1 \mathrm{xi})$ holds with $n=1$. Such an $x_{1}$ exists since $\gamma_{1}(x) / x \rightarrow \infty$. Define $\varphi\left(x_{1}\right)=1$. We note (3.1 i), (3.1 ii), (3.1 ix), and (3.1 xi) are satisfied for $n=1$ and $(3.1 \mathrm{v})$ holds with $x=x_{1}$.

We now suppose for some positive integer $p$ that we have a sequence of positive integers $M_{1}, M_{2}, \cdots, M_{p+1}$, a second sequence of positive integers $x_{1}, x_{2}, \cdots, x_{p}$, an increasing sequence $\beta_{1}, \beta_{2}, \cdots, \beta_{p}$ of positive numbers less than 1 , and a function $\varphi:\left[x_{1}, x_{p}\right] \rightarrow[1, \infty)$. In addition we suppose (3.1 i), (3.1 ii), (3.1 ix), and (3.1 xi) hold for $n \leqq p$, (3.1 iii), (3.1 iv), (3.1 vi), (3.1 viii), (3.1 x) hold for positive $n \leqq p-1$, that (3.1 v) holds for $x_{1} \leqq x \leqq x_{p}$, and that (3.1 vii) holds for $x_{1}+4 \leqq x<x_{p}$. These hypotheses are satisfied in the case $p=1$, vacuously in the case of (3.1 iii), (3.1 iv), (3.1 vi), (3.1 viii), (3.1 x), and (3.1 vii).

We define numbers $\beta_{p+1}, M_{p+2}$, and $x_{p+1}$ and extend the definition of $\varphi$ to $\left(x_{p}, x_{p+1}\right]$ in the following manner. We choose $\beta_{p+1} \in\left(\beta_{p}, 1\right)$ such that (3.1 iv) holds with $n=p$. We then let $M_{p+2}$ be an integer such that $(3.1$ i) and (3.1 ii) hold with $n=p+1$. We next choose

$$
x_{p+1}>8 x_{p}+8\left(\frac{1}{2} \log M_{p+1}-2 \log M_{p}\right)
$$

such that (3.1 iii) and (3.1 $\mathrm{x})$ hold with $n=p$ and $(3.1 \mathrm{xi})$ holds with $n=p+1$.

We now define $\varphi$ on $\left(x_{p}, x_{p+1}\right]$. Recalling that $\varphi^{\prime}$ denotes the right derivative, we specify

$$
\varphi^{\prime}\left(x_{p}\right)=M_{p}^{2}
$$

and

$$
\varphi^{\prime}\left(8 x_{p}+4 k\right)=2^{k} M_{p}^{2}, \quad k=0,1,2, \cdots, k_{p},
$$

where $k_{p}$ is the largest integer $k$ such that

$$
2^{k+1} M_{p}^{2}<M_{p+1}^{1 / 2} \text {. }
$$

We note from (3.2) and (3.5) that

$$
8 x_{p}+4\left(k_{p}+1\right)<8 x_{p}+8\left(\frac{1}{2} \log M_{p+1}-2 \log M_{p}\right)<x_{p+1} .
$$

We define $\varphi$ on $\left(x_{p}, x_{p+1}\right]$ to be the unique function satisfying (3.1 vi) with $n=p$, (3.3), (3.4), and

$$
\varphi^{\prime}(x)=M_{p+1}^{1 ; 2}, \quad 8 x_{p}+4\left(k_{p}+1\right) \leqq x<x_{p+1} .
$$


Thus (3.1 viii) holds with $n=p$ and (3.1 ix) holds with $n=p+1$.

In the case $p=1$, we observe that (3.1 v) holds for $x_{p} \leqq x \leqq x_{p+1}$ by virtue of (3.1 xi) with $n=1$ and (3.1 viii) with $n=1$, since $x_{1} \leqq x \leqq x_{2}$ implies

$$
\varphi(x) \leqq 1+M_{2}^{1 / 2}\left(x-x_{1}\right) \leqq 4 M_{2} x \leqq \gamma_{1}(x) .
$$

If $p \geqq 2$, (3.1 viii) with $n=p-1$ implies

$$
\varphi\left(x_{p}\right) \leqq \varphi\left(x_{p-1}\right)+M_{p}^{1 / 2}\left(x_{p}-x_{p-1}\right),
$$

which in conjunction with (3.1 $\mathrm{x})$ with $n=p-1$ and (3.1 viii) with $n=p$ implies $(3.1 \mathrm{v})$ holds for $x_{p} \leqq x \leqq x_{p+1}$.

Finally we observe that (3.1 vii) holds for $x_{1}+4 \leqq x<x_{p+1}$. If $p=1$, this is a result of (3.4) and (3.6) with $p=1$. For $p \geqq 2$, inequality (3.1 vii) holds for $x_{p} \leqq x<x_{p+1}$ by (3.4) and (3.6), with equality holding for $x_{p} \leqq x<x_{p}+4$.

This finishes the inductive step of the proof. We have (3.1 i), (3.1 ii), (3.1 ix), and (3.1 xi) holding with $n=p+1$ and (3.1 iii), (3.1 iv), (3.1 vi), (3.1 viii), and $(3.1 \mathrm{x})$ holding with $n=p$. In addition (3.1 v) holds for $x_{1} \leqq x \leqq x_{p+1}$ and (3.1 vii) holds for $x_{1}+4 \leqq x<x_{p+1}$. Finally we notice that the convexity of $\varphi$ follows from (3.1 vi) and (3.1 viii), and that $\beta_{n} \rightarrow 1$ by (3.1 iv). This completes the proof of Lemma 3.1. In what follows we shall make no use of $(3.1 \mathrm{x})$. It is included only as an aid in the inductive step of the proof of the lemma.

We now use the lemma to prove the theorem. It is elementary that corresponding to $\kappa$ of Theorem 2, there exists a nondecreasing $\gamma:(0, \infty) \rightarrow(0, \infty)$ and $x^{\prime}>0$ such that

$$
\frac{\gamma(x)}{x}<\kappa\left(e^{x}\right), \quad x>x^{\prime},
$$

and $\gamma(x) / x \rightarrow \infty$ as $x \rightarrow \infty$. We apply Lemma 3.1 to this $\gamma$ and define

$$
n(t)=\left\{\begin{array}{cl}
0 & 0 \leqq t<e^{x_{1}} \\
{\left[e^{\varphi(\log t)} \varphi^{\prime}(\log t)\right]} & e^{x_{1}} \leqq t
\end{array}\right.
$$

We note that $n(t)$ is nondecreasing and continuous from the right on $[0, \infty)$. We shall construct an entire $f$ with positive zeros and $n(t, 1 / f)=n(t)$.

We define $N(r)=\int_{0}^{r}(n(t) / t) d t$ and note for $\log r>x_{1}$ that

$$
N(\boldsymbol{r})=(1-\theta(r)) \exp (\varphi(\log r))
$$

for some $0<\theta(r)<1$ with $\theta(r) \rightarrow 0$ as $r \rightarrow \infty$. It follows immediately from (3.8) and the definition of $n(t)$ that 


$$
\frac{d(\log N(t))}{d(\log t)}=\frac{n(t)}{N(t)}=(1+o(1)) \varphi^{\prime}(\log t)
$$

and

$$
\varphi(\log t)=\log N(t)+o(1) .
$$

From (3.1 vii) and the convexity of $\varphi$ we thus obtain

$$
\begin{aligned}
n(t) / N(t) & =(1+o(1)) \varphi^{\prime}(\log t) \leqq(1+o(1))\left(\phi^{\prime}(-1+\log t)\right)^{4} \\
& \leqq(1+o(1))(\varphi(\log t))^{4} \leqq(1+o(1))(\log N(t))^{4}
\end{aligned}
$$

Let $\alpha(x)=\varphi(x) / x$. The convexity of $\varphi$ together with $\varphi^{\prime}\left(x_{1}\right)>$ $\alpha\left(x_{1}\right)$ implies $\alpha$ is continuous and strictly increasing on $\left[x_{1}, \infty\right)$. By (3.1 viii) certainly $\alpha$ is unbounded on $\left[x_{1}, \infty\right)$. Thus, for $m=$ $1,2,3, \cdots$, we may define a strictly increasing, unbounded sequence $s_{m}$ by specifying $s_{m}$ to be the unique solution of

$$
\alpha(\log t)=m / 2 \text {. }
$$

From (3.8) and (3.12) it follows that

$$
N(t)<t^{m / 2}, \quad 0<t \leqq s_{m} .
$$

In view of (3.11) and (3.13)

$$
n\left(s_{m}\right) \leqq(1+o(1)) N\left(s_{m}\right)\left(\log N\left(s_{m}\right)\right)^{4}=o\left(s_{m}^{3 m / 4}\right),
$$

implying the existence of $A>0$ such that for $m=1,2,3, \cdots$

$$
\frac{n\left(s_{m}\right)+N\left(s_{m}\right)}{s_{m}^{m}}<\frac{A}{s_{m}^{m / 4}} .
$$

We let $0<z_{1} \leqq z_{2} \leqq z_{3} \leqq \cdots$ be the nondecreasing sequence of positive numbers with counting function $n(t)$. For $z_{\nu} \leqq s_{1}$, we let $q_{\nu}=0$. For $m \geqq 2$, we let $q_{\nu}=m-1$ if $s_{m-1}<z_{\nu} \leqq s_{m}$. We define

$$
g(z)=\prod_{\nu} E\left(\frac{z}{z_{\nu}}, q_{\nu}\right) \text {. }
$$

In view of (3.11), (3.13), and the choice of $q_{\nu}$, an argument (with $n(t)$ replacing $\left.\tilde{n}_{j}(t)\right)$ virtually identical to that leading to (2.15) shows $g$ to be entire.

We now define a sequence $r_{n}$ tending to infinity. For $n \geqq 1$ we select

$$
x_{n}^{\prime} \in\left(x_{n}, 2 x_{n}\right)
$$

satisfying

$$
\alpha\left(x_{n}^{\prime}\right)=M_{n} \text {. }
$$


Since

$$
\alpha\left(2 x_{n}\right)>\frac{\varphi\left(2 x_{n}\right)-\varphi\left(x_{n}\right)}{2 x_{n}}=\frac{1}{2} \varphi^{\prime}\left(x_{n}\right)=\frac{M_{n}^{2}}{2}
$$

by (3.1 vi) and (3.1 viii), we see from (3.1 ix) and the continuity of $\alpha$ that such an $x_{n}^{\prime}$ exists.

We let

$$
r_{n}=\exp x_{n}^{\prime}
$$

For notational convenience we let $\rho_{n}=\varphi^{\prime}\left(x_{n}^{\prime}\right)$ and note by (3.1 vi) and (3.1 viii) that $\rho_{n}=M_{n}^{2}$. From (3.8), (3.16), and (3.17) we have

$$
N\left(r_{n}\right)=(1-o(1)) r_{n}^{M} \text {. }
$$

For each $n=1,2,3, \cdots$, we now define a finite sequence $a_{m n}$, $1 \leqq m \leqq M_{n+1}$, as follows. For $1 \leqq m \leqq 2 M_{n}$, let

$$
a_{m n}=\frac{n\left(s_{m}\right)}{m s_{m}^{m}}+\frac{N\left(s_{m}\right)}{s_{m}^{m}}+\frac{2 N\left(r_{n}\right)}{r_{n}^{m}}\left(\beta_{n}^{m}-1\right) .
$$

For $2 M_{n}<m \leqq M_{n+1}$, define

$$
\begin{aligned}
a_{m n}= & \frac{n\left(s_{m}\right)}{m s_{m}^{m}}+\frac{N\left(s_{m}\right)}{s_{m}^{m}}+\frac{2 N\left(r_{n}\right)}{r_{n}^{m}}\left(\beta_{n}^{m}-1\right) \\
& +m \int_{r_{n}}^{s_{m}} \frac{N(t)}{t^{m+1}} d t+m \int_{0}^{r_{n}}\left(\frac{t}{r_{n}^{2}}\right)^{m} \frac{N(t)}{t} d t .
\end{aligned}
$$

We note that $s_{m}>r_{n}$ if and only if $m>2 M_{n}$. This is a consequence of the monotonicity of $\alpha$ and the fact that $\alpha\left(\log s_{m}\right)=m / 2$ and $\alpha\left(\log r_{n}\right)=M_{n}$.

We now estimate the size of $a_{m n}$ for $n \geqq 2$. For $1 \leqq m \leqq M_{n}$, by (3.1 iv) and (3.14)

$$
\begin{aligned}
\left|a_{m n}\right| & <\frac{A}{s_{m}^{m / 4}}+\frac{2 N\left(r_{n}\right)}{r_{n}^{m}}\left(1-\beta_{n}^{M n}\right) \\
& <\frac{A}{s_{m}^{m / 4}}+\frac{2 N\left(r_{n}\right)}{r_{n}^{m}} e^{-4 m x_{n-1}} .
\end{aligned}
$$

For $M_{n}<m \leqq 2 M_{n}$, from (3.1 iv), (3.14), and (3.18)

$$
\left|a_{m n}\right|<\frac{A}{s_{m}^{m / 4}}+2\left(1-\beta_{n}^{m}\right) \leqq \frac{A}{s_{m}^{m / 4}}+2 e^{-4 m x_{n-1}} .
$$

For $2 M_{n}<m \leqq M_{n+1}$, (3.18) implies

$$
\frac{N\left(r_{n}\right)}{r_{n}^{m}}\left(1-\beta_{n}^{m}\right) \leqq r_{n}^{M n^{-m}}<r_{n}^{-m / 2}
$$


Elementary integration and (3.13) imply

$$
m \int_{r_{n}}^{s_{m}} \frac{N(t)}{t^{m+1}} d t+m \int_{0}^{r_{n}}\left(\frac{t}{r_{n}^{2}}\right)^{m} \frac{N(t)}{t} d t \leqq \frac{8}{3} r_{n}^{-m / 2} .
$$

From (3.14), (3.23), and (3.24) we conclude for $2 M_{n}<m \leqq M_{n+1}$ that

$$
\left|a_{m n}\right|<\frac{A}{s_{m}^{m / 4}}+\frac{5}{r_{n}^{m / 2}} .
$$

Our choice of $a_{m n}$ is motivated by the fact that if

$$
h_{n}(z)=\sum_{m=1}^{M_{n+1}} a_{m n} z^{m}
$$

then

$$
c_{m}\left(r_{n}, e^{h_{n}} g\right)= \begin{cases}\beta_{n}^{m} N\left(r_{n}\right)+A_{m n} & 1 \leqq m \leqq 2 M_{n} \\ \beta_{n}^{m} N\left(r_{n}\right) & 2 M_{n}<m \leqq M_{n+1}\end{cases}
$$

where for $1 \leqq m \leqq 2 M_{n}$

$$
A_{m n}=\frac{m}{2} \int_{s_{m}}^{r_{n}}\left(\frac{r_{n}}{t}\right)^{m} \frac{N(t)}{t} d t-\frac{m}{2} \int_{0}^{r_{n}}\left(\frac{t}{r_{n}}\right)^{m} \frac{N(t)}{t} d t .
$$

In fact if $F(z)=e^{I L(z)} g(z)$ where $H(z)=\sum b_{m} z^{m}$, then, since $q_{\nu}<m$ is equivalent to $x_{2} \leqq s_{m}$, calculations similar to those involved in (2.18) and (2.19) show that

$$
\begin{aligned}
c_{m}(r, F)= & r^{m}\left\{\frac{b_{m}}{2}-\frac{n\left(s_{m}\right)}{2 m s_{m}^{m}}-\frac{N\left(s_{m}\right)}{2 s_{m}^{m}}\right\}+N(r) \\
& +\frac{m}{2} \int_{s_{m}}^{r}\left(\frac{r}{t}\right)^{m} \frac{N(t)}{t} d t-\frac{m}{2} \int_{0}^{r}\left(\frac{t}{r}\right)^{m} \frac{N(t)}{t} d t .
\end{aligned}
$$

In view of (3.19) and (3.20), (3.26) is a special case of (3.27).

We now show

$$
\left(\sum_{m=1}^{2 M_{n}} A_{m n}^{2}\right)^{1 / 2}=o\left(N\left(r_{n}\right)\right)
$$

We begin by recalling, from the remarks following (3.20), that $1 \leqq m \leqq 2 M_{n}$ is equivalent to $s_{m} \leqq r_{n}$. From (3.1 vi), (3.1 viii), (3.10), and (3.15) it follows that uniformly on the interval $e^{x_{n}} \leqq t \leqq r_{n}$ we have as $n$ tends to infinity

$$
N(t)=(1+o(\mathbf{1})) N\left(r_{n}\right)\left(t / r_{n}\right)^{\rho_{n}} .
$$

First suppose $m \leqq 2 M_{n}$ is such that $e^{x_{n}} \leqq s_{m} \leqq r_{n}$. We write $A_{m n}=B_{m n}+C_{m n}$ where

$$
B_{m n}=\frac{m}{2} \int_{s_{m}}^{r_{n}}\left(\frac{\boldsymbol{r}_{n}}{t}\right)^{m} \frac{N(t)}{t} d t-\frac{m}{2} \int_{e^{x_{n}}}^{r_{n}}\left(\frac{t}{r_{n}}\right)^{m} \frac{N(t)}{t} d t
$$


and

$$
C_{m n}=-\frac{m}{2} \int_{0}^{e^{x_{n}}}\left(\frac{t}{r_{n}}\right)^{m} \frac{N(t)}{t} d t
$$

Elementary integration and (3.29) imply uniformly for the values of $m$ under consideration

$$
-(1+o(1)) \frac{m}{2\left(\rho_{n}+m\right)} N\left(r_{n}\right) \leqq B_{m n} \leqq(1+o(1)) \frac{m}{2\left(\rho_{n}-m\right)} N\left(r_{n}\right) .
$$

In addition, uniformly in $m$

$$
\left|C_{m n}\right| \leqq \frac{N\left(e^{x_{n}}\right)}{2} \leqq(1+o(1)) N\left(r_{n}\right)^{1 / 2}
$$

where the last inequality is a result of (3.1 ix), (3.10), (3.15), (3.17), and (3.18). Since $\rho_{n}=M_{n}^{2}$, (3.18), (3.30), and (3.31) imply

$$
\begin{aligned}
& \left(\sum_{e^{x} \leqq_{m} \leqq r_{n}} A_{m n}^{2}\right)^{1 / 2} \leqq\left(\sum_{e^{x} \leqq_{s_{m} \leqq r_{n}}} B_{m n}^{2}\right)^{1 / 2}+\left(\sum_{e^{x_{n}} \sum_{s_{m} \leqq r_{n}}} C_{m n}^{2}\right)^{1 / 2} \\
& \leqq\left(\frac{1}{2}+o(1)\right)\left(\sum_{m=1}^{2 M_{n}}\left(\frac{m}{\rho_{n}-m}\right)^{2}\right)^{1 / 2} N\left(r_{n}\right)+(1+o(1))\left(2 M_{n} N\left(r_{n}\right)\right)^{1 / 2} \\
& =O\left(\frac{M_{n}^{3}}{\rho_{n}^{2}}\right)^{1 / 2} N\left(r_{n}\right)+o\left(N\left(r_{n}\right)\right)=o\left(N\left(r_{n}\right)\right) .
\end{aligned}
$$

For $m$ such that $s_{m}<e^{x}$, we write $A_{m n}=B_{m n}^{\prime}+C_{m n}^{\prime}$, where

$$
B_{m n}^{\prime}=\frac{m}{2} \int_{s_{m}}^{r_{n}}\left(\frac{r_{n}}{t}\right)^{m} \frac{N(t)}{t} d t-\frac{m}{2} \int_{s_{m}}^{r_{n}}\left(\frac{t}{r_{n}}\right)^{m} \frac{N(t)}{t} d t
$$

and

$$
C_{m n}^{\prime}=-\frac{m}{2} \int_{0}^{s_{m}}\left(\frac{t}{r_{n}}\right)^{m} \frac{N(t)}{t} d t
$$

From (3.29) we have uniformly in $m$

$$
\begin{aligned}
0 \leqq & B_{m_{n}}^{\prime} \leqq \frac{m}{2} \int_{s_{m}}^{e^{x_{n}}}\left(\frac{r_{n}}{t}\right)^{m} \frac{N\left(e^{x_{n}}\right)}{t} d t \\
& +\frac{m}{2} \int_{e^{x_{n}}}^{r_{n}}\left(\frac{r_{n}}{t}\right)^{m} \frac{N(t)}{t} d t \leqq \frac{N\left(e^{x_{n}}\right) r_{n}^{m}}{2}+(1+o(1)) \frac{m N\left(r_{n}\right)}{2\left(\rho_{n}-m\right)} .
\end{aligned}
$$

We note that $m \geqq 2 M_{n}^{1 / 2}$ implies by (3.1 ix)

$$
\alpha\left(x_{n}\right) \leqq M_{n}^{1 / 2} \leqq m / 2=\alpha\left(\log s_{m}\right) .
$$

Thus for $s_{m}<e^{x_{n}}$ we have $m<2 M_{n}^{1 / 2}$, and hence by (3.18) and the right half of (3.31)

$$
N\left(e^{x_{n}}\right) r_{n}^{m}=o\left(N\left(r_{n}\right)\right)^{3 / 4}
$$


As before,

$$
\left|C_{m n}^{\prime}\right| \leqq \frac{N\left(e^{x_{n}}\right)}{2} \leqq(1+o(1)) N\left(r_{n}\right)^{1 / 2}
$$

As in (3.32), the combination of (3.33), (3.35), and (3.36) yields

$$
\left(\sum_{s_{m}<e} A_{n}^{2} A_{m n}^{1 / 2}=o\left(N\left(r_{n}\right)\right),\right.
$$

which in conjunction with (3.32) establishes (3.28).

We note that the combination of (3.26) and (3.28) gives

$$
\left(\sum_{m=1}^{M r_{n+1}}\left|c_{m}\left(r_{n}, e^{h_{n}} g\right)-\beta_{n}^{m} N\left(r_{n}\right)\right|^{2}\right)^{1 / 2}=o\left(N\left(r_{n}\right)\right) .
$$

We now define $f$. We let

$$
a_{m}= \begin{cases}a_{m 1} & 1 \leqq m \leqq M_{2} \\ a_{m n} & M_{n}<m \leqq M_{n+1}, n \geqq 2 .\end{cases}
$$

Letting $h(z)=\sum a_{m} z^{m}$, we note from (3.22) and (3.25) that $h$ is entire. We define

$$
f(z)=e^{h(z)} g(z) .
$$

In order to show $N\left(r_{n}\right) / T\left(r_{n}, f\right) \rightarrow 1$, and hence $d(0, f)=0$, we need an additional property of $g$, namely

$$
\left(\sum_{m>M_{n+1}}\left|c_{m}\left(r_{n}, g\right)\right|^{2}\right)^{1 / 2}=o\left(N\left(r_{n}\right)\right) .
$$

We first note from (3.1 iii), (3.15), and (3.34) that $m>M_{n+1}$ implies

$$
s_{m}^{1 / 4}>e^{\left(x_{n+1}\right) / 4}>2 r_{n} .
$$

We consider (3.27) with $b_{m}=0$ and $r=r_{n}$. From (3.14) and (3.40) we have for $m>M_{n+1}$

$$
r_{n}^{m}\left(\frac{n\left(s_{m}\right)}{2 m s_{m}^{m}}+\frac{N\left(s_{m}\right)}{2 s_{m}^{m}}\right) \leqq A\left(\frac{r_{n}}{s_{m}^{1 / 4}}\right)^{m}<\frac{A}{2^{m}} .
$$

In addition by (3.9), (3.10), and the convexity of $\varphi$ there exists a positive constant $t_{0}$ independent of $n$ such that as $n \rightarrow \infty$

$$
N(t) \geqq N\left(r_{n}\right)\left(\frac{t}{r_{n}}\right)^{\rho_{n}(1+o(1))}
$$

uniformly for $t_{0} \leqq t \leqq r_{n}$. Consequently, uniformly for $m>M_{n+1}$ as $n \rightarrow \infty$ 


$$
\begin{aligned}
0 & \leqq \frac{N\left(r_{n}\right)}{2}-\frac{m}{2} \int_{0}^{r_{n}}\left(\frac{t}{r_{n}}\right)^{m} \frac{N(t)}{t} d t \\
& \leqq \frac{N\left(r_{n}\right)}{2}-\frac{m N\left(r_{n}\right)}{2} \int_{t_{0}}^{r_{n}}\left(\frac{t}{r_{n}}\right)^{m+\rho_{n}(1+o(1))} \frac{d t}{t} \\
& \leqq(1+o(1)) \frac{\rho_{n}\left(N\left(r_{n}\right)\right)}{2\left(\rho_{n}+m\right)}+\frac{1}{2^{m}}
\end{aligned}
$$

where we have used (3.18).

For $m>M_{n+1}$, we have $s_{m}>e^{8 x_{n}}$ by (3.1 iii) and (3.34), and consequently by (3.13) and (3.15)

$$
\frac{m}{2} \int_{e^{8 x_{n}}}^{s_{m}}\left(\frac{r_{n}}{t}\right)^{m} \frac{N(t)}{t} d t \leqq\left(\frac{r_{n}}{e^{4 x_{n}}}\right)^{m}<\frac{1}{2^{m}} .
$$

Uniformly for $m>M_{n+1}$ we have by (3.1 vi), (3.9), and (3.15) as $n \rightarrow \infty$

$$
\begin{aligned}
& \frac{m}{2} \int_{r_{n}}^{e^{8 x_{n}}}\left(\frac{r_{n}}{t}\right)^{m} \frac{N(t)}{t} d t \\
& \quad=\frac{m N\left(r_{n}\right)}{2} \int_{r_{n}}^{e^{8 x_{n}}}\left(\frac{r_{n}}{t}\right)^{m-\rho_{n}(1+o(1))} \frac{d t}{t} \\
& \quad=\frac{m N\left(r_{n}\right)}{2\left(m-\rho_{n}(1+o(1))\right)}+o\left(\frac{1}{2^{m}}\right) .
\end{aligned}
$$

Combining (3.43) and (3.44), we obtain uniformly for $m>M_{n+1}$

$$
\left|\frac{N\left(r_{n}\right)}{2}-\frac{m}{2} \int_{r_{n}}^{s_{m}}\left(\frac{r_{n}}{t}\right)^{m} \frac{N(t)}{t} d t\right| \leqq(1+o(1)) \frac{\rho_{n} N\left(r_{n}\right)}{2\left(m-\rho_{n}\right)}+\frac{1}{2^{m-1}} .
$$

The combination of (3.42) and (3.45) yields uniformly for $m>M_{n+1}$

$$
\begin{gathered}
\left|N\left(r_{n}\right)-\frac{m}{2} \int_{r_{n}}^{s_{m}}\left(\frac{r_{n}}{t}\right)^{m} \frac{N(t)}{t} d t-\frac{m}{2} \int_{0}^{r_{n}}\left(\frac{t}{r_{n}}\right)^{m} \frac{N(t)}{t} d t\right| \\
\leqq(1+o(1)) \frac{N\left(r_{n}\right)}{2}\left(\frac{\rho_{n}}{m-\rho_{n}}+\frac{\rho_{n}}{m+\rho_{n}}\right)+\frac{1}{2^{m-2}} .
\end{gathered}
$$

Since $\rho_{n}=M_{n}^{2}$, we see from (3.1 i), (3.27), (3.41), (3.46) and the Schwarz inequality that as $n \rightarrow \infty$

$$
\left(\sum_{m>M_{n+1}}\left|c_{m}\left(r_{n}, g\right)\right|^{2}\right)^{1 / 2}=O\left(\frac{\rho_{n}}{M_{n+1}^{1 / 2}} N\left(r_{n}\right)\right)+o(1)=o\left(N\left(r_{n}\right)\right),
$$

establishing (3.39).

We next observe that

$$
\left\|\log \left|f\left(r_{n} e^{i \theta}\right)\right|-\operatorname{Re} \frac{1+\beta_{n} e^{i \theta}}{1-\beta_{n} e^{i \theta}} N\left(r_{n}\right)\right\|_{1}^{2}
$$




$$
\begin{aligned}
& \leqq\left\|\log \left|f\left(r_{n} e^{i \theta}\right)\right|-\operatorname{Re} \frac{1+\beta_{n} e^{i \theta}}{1-\beta_{n} e^{i \theta}} N\left(r_{n}\right)\right\|_{2}^{2} \\
& =2 \sum_{m=1}^{M_{n+1}}\left|c_{m}\left(r_{n}, f\right)-\beta_{n}^{m} N\left(r_{n}\right)\right|^{2}+2 \sum_{m>M_{n+1}}\left|c_{m}\left(r_{n}, f\right)-\beta_{n}^{m} N\left(r_{n}\right)\right|^{2} \\
& \equiv 2 I_{n}+2 I I_{n} .
\end{aligned}
$$

To analyze $I I_{n}$, we first note from (3.15), (3.22), (3.25), (3.38), and (3.40) that

$$
\left|a_{m}\right|<B\left(2 r_{n}\right)^{-m}
$$

for some constant $B>0$ independent of $n$ for all $m>M_{n+1}$. Thus by (3.1 ii), (3.39), and (3.48)

$$
\begin{aligned}
I I_{n}^{1 / 2} & \leqq\left(\sum_{m>M_{n+1}}\left|c_{m}\left(r_{n}, g\right)\right|^{2}\right)^{1 / 2} \\
& +\frac{B}{2}\left(\sum_{m>M_{n+1}} 2^{-2 m}\right)^{1 / 2}+\left(\sum_{m>M_{n+1}} \beta_{n}^{2 m}\right)^{1 / 2} N\left(r_{n}\right)=o\left(N\left(r_{n}\right)\right) .
\end{aligned}
$$

From the definitions of $h_{n}$ and $I_{n}$ we have

$$
I_{n}^{1: 2}=\left(\sum_{m=1}^{M n+1}\left|c_{m}\left(r_{n}, e^{h} g\right)-\beta_{n}^{m} N\left(r_{n}\right)+\left(\frac{a_{m}-a_{m n}}{2}\right) r_{n}^{m}\right|^{2}\right)^{1 / 2} .
$$

By (3.37) and (3.38) we have

$$
I_{n}^{1 / 2} \leqq o\left(N\left(r_{n}\right)\right)+\frac{1}{2}\left(\sum_{m=1}^{I_{n}}\left|a_{m}\right|^{2} r_{n}^{2 m}\right)^{1 / 2}+\frac{1}{2}\left(\sum_{m=1}^{M n}\left|a_{m n}\right|^{2} r_{n}^{2 m}\right)^{1 / 2} .
$$

From (3.18) and (3.21) we have

$$
\begin{aligned}
& \left(\sum_{m=1}^{M_{n}}\left|a_{m n}\right|^{2} r_{n}^{2 m}\right)^{1 / 2} \\
& \quad \leqq o\left(N\left(r_{n}\right)\right)+A\left(\sum_{m=1}^{M_{n} / 2} \frac{r_{n}^{2 m}}{s_{m}^{m / 2}}\right)^{1 / 2}+A\left(\sum_{m=M_{n} / 2}^{M_{n}} \frac{r_{n}^{2 m}}{s_{m}^{m / 2}}\right)^{1 / 2} \\
& \quad \leqq o\left(N\left(r_{n}\right)\right)+O\left(M_{n}^{1 / 2} r_{n}^{W n^{\prime 2}}\right)+o\left(N\left(r_{n}\right)\right)=o\left(N\left(r_{n}\right)\right) .
\end{aligned}
$$

Similarly

$$
\begin{aligned}
& \left(\sum_{m=1}^{M_{n}}\left|a_{m}\right|^{2} r_{n}^{2 m}\right)^{1 / 2} \leqq O\left(M_{n}^{1 / 2} r_{n_{n}}^{M n_{n} / 2}\right) \\
& \quad+\left(\sum_{m=M_{n} / 2}^{M_{n}}\left|a_{m}\right|^{2}\right)^{1 / 2} r_{n}^{M n}=o\left(N\left(r_{n}\right)\right) .
\end{aligned}
$$

The combination of (3.47), (3.49), (3.50), (3.51), and (3.52) yields

$$
\left\|\log \left|f\left(r_{n} e^{i \theta}\right)\right|-\operatorname{Re} \frac{1+\beta_{n} e^{i \theta}}{1-\beta_{n} e^{i \theta}} N\left(r_{n}\right)\right\|_{1}=o\left(N\left(r_{n}\right)\right),
$$

trivially implying $m\left(r_{n}, 1 / f\right)=o\left(N\left(r_{n}\right)\right)$ and hence $d(0, f)=0$. 
For the remainder of the proof, we reserve the letter $r$ for a value satisfying

$$
x_{n} \leqq \log r=x_{n}+4 q \leqq x_{n+1} / 4
$$

for some integers $q$ and $n$. We must show

$$
\log T(\tilde{r}, f)<\gamma(\log \tilde{r}), \quad \tilde{r}>R_{0},
$$

which in conjunction with (3.7) establishes (4).

We consider $c_{m}(r, f)$ given by (3.27) with $b_{m}=a_{m}$. For $m \leqq$ $2 M_{n+1}$, from (3.14) and the fact that $a_{m} \rightarrow 0$ we conclude

$$
\left|r^{m}\left(\frac{a_{m}}{2}-\frac{n\left(s_{m}\right)}{2 m s_{m}^{m}}-\frac{N\left(s_{m}\right)}{2 s_{m}^{m}}\right)\right|=O\left(r^{m}\right)=O\left(r^{2 M_{n+1}}\right) .
$$

Noting

$$
\frac{m}{2} \int_{0}^{s_{m}}\left(\frac{r}{t}\right)^{m} \frac{N(t)}{t} d t<r^{m}
$$

by (3.13), we see from (3.10), (3.18), and the monotonicity of $\alpha$ that for $1 \leqq m \leqq 2 M_{n+1}$

$$
\begin{aligned}
& \left|N(r)+\frac{m}{2} \int_{0}^{r}\left(\left(\frac{r}{t}\right)^{m}-\left(\frac{\mathrm{t}}{r}\right)^{m}\right) \frac{N(t)}{t} d t-\frac{m}{2} \int_{0}^{s_{m}}\left(\frac{r}{t}\right)^{m} \frac{N(t)}{t} d t\right| \\
& \leqq r^{m} N(r) \leqq r^{3 . M_{n+1}} .
\end{aligned}
$$

By $(3.1 \mathrm{xi}),(3.56)$, and (3.57)

$$
\left(\sum_{|m| \leqq 2 M}\left|c_{m+1}(r, f)\right|^{2}\right)^{1 / 2}=o\left(r^{4 M_{n+1}}\right)=o\left(e^{\gamma_{1}(\log r)}\right) .
$$

From the definition of $a_{m}$, (3.1 iv), (3.23), (3.24), and (3.54) we have for $m>2 M_{n+1}$

$$
\left|r^{m}\left(\frac{a_{m}}{2}-\frac{n\left(s_{m}\right)}{2 m s_{m}^{m}}-\frac{N\left(s_{m}\right)}{2 s_{m}^{m}}\right)\right|<\frac{5}{2}\left(\frac{r}{r_{n+1}^{1 / 2}}\right)^{m}<\frac{1}{2^{m+1}} .
$$

We have

$$
s_{m}>e^{x_{n+1}}>e^{4} r
$$

for $m>2 M_{n+1}$ by (3.34). By (3.1 vi), (3.1 viii), (3.9), and (3.54) uniformly for $m>2 M_{n+1}$

$$
\begin{aligned}
& \frac{N(r)}{2}-\frac{m}{2} \int_{r}^{e^{4} r}\left(\frac{r}{t}\right)^{m} \frac{N(t)}{t} d t \\
& \quad=\frac{N(r)}{2}\left(1-m \int_{r}^{e^{4} r}\left(\frac{r}{t}\right)^{m-\rho_{r}(1+o(1))} \frac{d t}{t}\right) \\
& \quad=-(1+o(1)) \frac{\rho_{r}}{2\left(m-\rho_{r}\right)} N(r)+o\left(\frac{N(r)}{e^{3 m}}\right)=-(1+o(1)) \frac{\rho_{r} N(r)}{2 m}
\end{aligned}
$$


where $\rho_{r}=\phi^{\prime}(\log r) \leqq(m / 2)^{1 / 2}$.

Since $e^{4} r<t<e^{x_{n+1}}$ implies

$$
N(t)<N\left(e^{4} r\right)\left(t / e^{4} r\right)^{M_{n+1}^{1 / 2}(1+o(1))}
$$

by (3.1 viii) and (3.9), we conclude by elementary integration

$$
\frac{m}{2} \int_{e^{4} r}^{e^{x} n+1}\left(\frac{r}{t}\right)^{m} \frac{N(t)}{t} d t \leqq \frac{N\left(e^{4} r\right)}{e^{4 m(1-o(1))}}
$$

uniformly for $m>2 M_{n+1}$ as $r$ tends to infinity through values satisfying (3.54). Finally from (3.13) and (3.54), for $m>2 M_{n+1}$

$$
\frac{m}{2} \int_{e^{x_{n+1}}}^{s_{m}}\left(\frac{r}{t}\right)^{m} \frac{N(t)}{t} d t<\frac{r^{m}}{e^{m\left(x_{n+1}\right) / 2}}<\frac{1}{2^{m}} .
$$

Combining (3.60), (3.61), and (3.62), we conclude from (3.1 viii)

$$
\begin{gathered}
\left(\sum_{|m|>2 M_{n+1}}\left|\frac{N(r)}{2}-\frac{m}{2} \int_{r}^{s_{m}}\left(\frac{r}{t}\right)^{m} \frac{N(t)}{t} d t\right|^{2}\right)^{1 / 2} \\
=O(N(r))+o\left(N\left(e^{4} r\right)\right)=o\left(N\left(e^{4} r\right)\right) .
\end{gathered}
$$

Since $N(r)<r^{m / 2}$ for $m>2 M_{n+1}$, a calculation similar to (3.42) shows uniformly for $m>2 M_{n+1}$

$$
\begin{aligned}
0 & \leqq \frac{N(r)}{2}-\frac{m}{2} \int_{0}^{r}\left(\frac{t}{r}\right)^{m} \frac{N(t)}{t} d t \\
& \leqq(1+o(1)) \frac{\rho_{r} N(r)}{2 m}+\frac{1}{2^{m}},
\end{aligned}
$$

implying

$$
\begin{gathered}
\left(\sum_{|m|>2 M}\left|\frac{N(r)}{2}-\frac{m}{2} \int_{0}^{r}\left(\frac{t}{r}\right)^{m} \frac{N(t)}{t} d t\right|^{2}\right)^{1 / 2} \\
=O(N(r))=o\left(N\left(e^{4} r\right)\right) .
\end{gathered}
$$

Combining (3.27), (3.59), (3.63), and (3.64) with the Schwarz inequality, we conclude

$$
\left(\sum_{|m|>2 M_{n+1}}\left|\boldsymbol{c}_{m}(r, f)\right|^{2}\right)^{1 / 2}=o\left(N\left(e^{4} r\right)\right)=o\left(e^{\varphi(4+\log r)}\right),
$$

where we use (3.10) in the second equality.

From (3.1 v), (3.58), and (3.65) we have

$$
\log m_{2}^{+}(r, f)<\gamma_{1}(4+\log r)
$$

for sufficiently large $r$ satisfying (3.54). For sufficiently large $\tilde{r}$ there thus exists $r$ with 


$$
\log r \in[\log \tilde{r}, 4 \log \tilde{r}]
$$

for which (3.66) holds. Thus for all $\widetilde{r}>R_{0}$,

$$
\begin{aligned}
& T(\widetilde{r}, f) \leqq T(r, f) \leqq m_{2}^{+}(r, f) \\
& \quad \leqq e^{\gamma_{1}(4+\log r)}=e^{r((\log r) / 4)} \leqq e^{r(\log \tilde{r})},
\end{aligned}
$$

establishing (3.55) and hence (4). It is clear that the lower order of $f$ is infinite because the lower order of $N(t)$ is infinite. This finishes the proof of Theorem 2.

\section{REFERENCES}

1. A. Edrei and W. H. J. Fuchs, On the growth of meromorphic functions with several deficient values, Trans. Amer. Math. Soc., 93 (1959), 292-328.

2. - On the maximum number of deficient values of certain classes of functions, Air Force Technical Report AFOSR TN 60-402.

3. A. Edrei, W. H. J. Fuchs and S. Hellerstein, Radial distribution of deficiencies of the values of a meromorphic function, Pacific J. Math., 11 (1961), 135-151.

4. A. A. Gol'dberg, Distribution of values and meromorphic functions with separated zeros and poles, Soviet Math., 2 (1961), 389-392.

5. A. A. Gol'dberg and I. Ostrovskii, The Distribution of Values of Meromorphic Functions, Izdat. Nauk, Moscow, 1971.

6. W. K. Hayman, Research Problems in Function Theory, Athlone Press, London, 1967.

7. S. Hellerstein and D. F. Shea, Minimal deficiencies for entire functions with radially distributed zeros, to appear.

8. T. Kobayashi, On the radial distribution of zeros and poles of a meromorphic function, Kodai Math. Sem. Rep., 26 (1974), 58-68.

9. J. Miles and D. F. Shea, An extremal problem in value distribution theory, Quart. J. Math. Oxford (2), 24 (1973), 377-383.

10. F. Nevanlinna, Bemerkungen zur Theorie der ganzen Funktionen endlicher Ordnung, Soc. Sci. Fenn. Comment. Phys.-Math. 2 Nr. 4, 1923.

11. M. Ozawa, Radial distribution of zeros and deficiency of a canonical product of finite genus, Kodai Math. Sem. Rep., 25 (1973), 502-512.

12. W. Rudin, Function Theory in Polydiscs, Benjamin, New York, 1969.

13. H. Weyl, Über die Gleichverteilung von Zahlen mod. Eins, Math. Annalen, 77 (1916), 313-352.

Received February 1, 1978. This research was supported in part by the National Science Foundation under grants MCS 76-07214 and MCS 77-03516 and by the University of Maryland.

UNIVERSITY OF ILLINOIS

URBANA, IL 61801 



\section{PACIFIC JOURNAL OF MATHEMATICS}

EDITORS

DONALD BABBITT (Managing Editor)

University of California

Los Angeles, California 90024

HUGo RossI

University of Utah

Salt Lake City, UT 84112

C. C. MOORE

J. DUGUNDJI

Department of Mathematics

University of Southern California

Los Angeles, California 90007

R. FinN AND J. MiLgraM

Stanford University

Stanford, California 94305

University of California

Berkeley, CA 94720

\section{ASSOCIATE EDITORS}

E. F. BrCKENBACH

B. H. NeUmanN

F. WOLF

K. YoshidA

\section{SUPPORTING INSTITUTIONS}

UNIVERSITY OF BRITISH COLUMBIA

UNIVERSITY OF SOUTHERN CALIFORNIA

CALIFORNIA INSTITUTE OF TECHNOLOGY

STANFORD UNIVERSITY

UNIVERSITY OF CALIFORNIA

UNIVERSITY OF HAWAII

MONTANA STATE UNIVERSITY

UNIVERSITY OF TOKYO

UNIVERSITY OF NEVADA, RENO

UNIVERSITY OF UTAH

NEW MEXICO STATE UNIVERSITY

WASHINGTON STATE UNIVERSITY

OREGON STATE UNIVERSITY

UNIVERSITY OF WASHINGTON

UNIVERSITY OF OREGON 


\section{Pacific Journal of Mathematics}

\section{Vol. 81, No. $1 \quad$ November, 1979}

Thomas E. Armstrong, Simplicial subdivision of infinite-dimensional compact cubes ..................................... 1

Herbert Stanley Bear, Jr., Approximate identities and pointwise convergence ................................

Richard David Bourgin, Partial orderings for integral representations on convex sets with the Radon-Nikodým property..................

Alan Day, Herbert S. Gaskill and Werner Poguntke, Distributive lattices

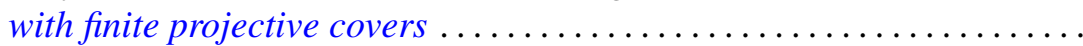

Heneri Amos Murima Dzinotyiweyi and Gerard L. G. Sleijpen, A note on measures on foundation semigroups with weakly compact orbits ......

Ronald James Evans, Resolution of sign ambiguities in Jacobi and Jacobsthal sums ...................................

John Albert Fridy, Tauberian theorems via block dominated matrices ......

Matthew Gould and Helen H. James, Automorphism groups retracting onto

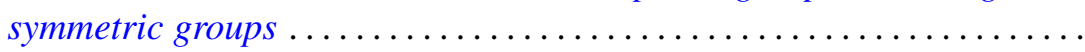

Kurt Kreith, Nonlinear differential equations with monotone solutions . . . . 101

Brian William McEnnis, Shifts on indefinite inner product spaces........ 113

Joseph B. Miles, On entire functions of infinite order with radially

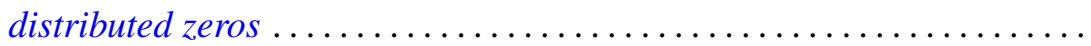

Janet E. Mills, The idempotents of a class of 0-simple inverse semigroups ...............................

Edward Jean Moulis, Jr., Generalizations of the Robertson functions ...

Richard A. Moynihan and Berthold Schweizer, Betweenness relations in probabilistic metric spaces.......................

Stanley Ocken, Perturbing embeddings in codimension two ....

Masilamani Sambandham, On the average number of real zeros of a class of random algebraic curves.

Jerry Searcy and B. Andreas Troesch, A cyclic inequality and a related eigenvalue problem.

Roger R. Smith and Joseph Dinneen Ward, $M$-ideals in $B\left(l_{p}\right)$...

Michel Talagrand, Deux généralisations d'un théorème de I. Namioka ..

Jürgen Voigt, $O n Y$-closed subspaces of $X$, for Banach spaces $X \subset Y$;

existence of alternating elements in subspaces of $C(J)$

Sidney Martin Webster, On mapping an $n$-ball into an $(n+1)$-ball in complex spaces

David J. Winter, Triangulable subalgebras of Lie p-algebras ... 